\title{
Enhanced Vibrating Particles System Algorithm for Parameters Estimation of Photovoltaic System
}

\section{Patrick Juvet Gnetchejo1, Salomé Ndjakomo Essiane ${ }^{1,2 *}$, Pierre Ele ${ }^{1,3}$, René Wamkeue ${ }^{3,4}$, Daniel Mbadjoun Wapet ${ }^{3}$, Steve Perabi Ngoffe ${ }^{1}$}

\author{
${ }^{1}$ Laboratory of Technologies and Applied Sciences, University of Douala, Douala, Cameroon \\ ${ }^{2}$ Higher Technical Teacher Training College of Ebolowa, University of Yaoundé, Yaoundé, Cameroon \\ ${ }^{3}$ Electrical Engineering and Telecommunications Department, National Advanced School of Engineering, University of Yaoundé, \\ Yaoundé, Cameroon \\ ${ }^{4}$ School of Engineering, University of Quebec in Abitibi-Temiscamingue (UQAT), Rouyn-Noranda, QC, Canada \\ Email: patrijuvet@yahoo.fr, ‘salomendjakomo@gmail.com, pierre_ele@yahoo.fr, rene.wamkeue@hotmail.com, \\ daniel_mbadjoun@univ-douala.com,ngoffeperabi@yahoo.fr
}

How to cite this paper: Gnetchejo, P.J., Essiane, S.N., Ele, P., Wamkeue, R., Wapet, D.M. and Ngoffe, S.P. (2019) Enhanced Vibrating Particles System Algorithm for Parameters Estimation of Photovoltaic System. Journal of Power and Energy Engineering, 7, 1-26.

https://doi.org/10.4236/jpee.2019.78001

Received: July 1, 2019

Accepted: August 17, 2019

Published: August 20, 2019

Copyright $\odot 2019$ by author(s) and Scientific Research Publishing Inc. This work is licensed under the Creative Commons Attribution International License (CC BY 4.0).

http://creativecommons.org/licenses/by/4.0/

\section{(c) (i) Open Access}

\begin{abstract}
To evaluate the performance of a photovoltaic panel, several parameters must be extracted from the photovoltaic. These parameters are very important for the evaluation, monitoring and optimization of photovoltaic. Among the methods developed to extract photovoltaic parameters from current-voltage (I-V) characteristic curve, metaheuristic algorithms are the most used nowadays. A new metaheuristic algorithm namely enhanced vibrating particles system algorithm is presented here to extract the best values of parameters of a photovoltaic cell. Five recent algorithms (grey wolf optimization (GWO), moth-flame optimization algorithm (MFOA), multi-verse optimizer (MVO), whale optimization algorithm (WAO), salp swarm-inspired algorithm (SSA)) are also implemented on the same computer. Enhanced vibrating particles system is inspired by the free vibration of the single degree of freedom systems with viscous damping. To extract the photovoltaic parameters using enhanced vibrating particles system algorithm, the problem can be set as an optimization problem with the objective to minimize the difference between measured and estimated current. Four case studies have been implemented here. The results and comparison with other methods exhibit high accuracy and validity of the proposed enhanced vibrating particles system algorithm to extract parameters of a photovoltaic cell and module.
\end{abstract}

\section{Keywords}

PV Cell Modeling, Vibrating Particles System, Parameter Estimation, 


\section{Introduction}

Many disadvantages affect the availability of fossil fuels: the fluctuating prices, the environmental pollution and the fact that they are not abundant [1]. The Energy produced by the sun is the most widespread, free and clean among all renewable energy resources. In recent years, interest to use PV as power generation has increased because of its many advantages [2]. Photovoltaic solar installations around the world are down from $89.5 \mathrm{GW}$ in 2012 to just over $303 \mathrm{GW}$ in 2016 [3]. The PV designers need reliable and accurate tools to predict the power produced by a PV [4]. A PV array comprises several photovoltaic cells connected in series and parallel according to the output power desired. Cells are made from semiconductor materials that produce an electric current when illuminated; the intensity of the current depends on the quantity of solar irradiance [5] [6]. Many factors like solar radiation [7], location latitude influence the output power of the solar system [8].

To design and assess the operation of a PV system, a PV model should be implemented with appropriate accurateness that one can employ to predict the reliable I-V and P-V output characteristics under normal operation [9]. To do this, many models have been developed in the literature. Several parameters need to be accurately extracted with good precision for the purpose to evaluate the performance of a PV system. These intrinsic parameters are: saturation current, series resistance, diode ideality factor saturation current, generated photocurrent and shunt resistance. As output power is proportional to solar irradiance, an estimate of the intrinsic parameters of the $\mathrm{PV}$ is necessary in order to evaluate its performance [10]. To extract these intrinsic parameters, we can use either the manufacturer's datasheet or experimentally measure the voltage and current from the PV [11].

Many methods in the literature have been developing to extract PV parameters. These methods can be classified into three categories: analytical methods, numerical methods and evolutionary methods. In the analytical method, a set of transcendental equations is solved to extract parameters from solar cell [12]. The main advantage of the analytical method is the speed of calculation and reasonably accurate results. Analytical methods are simple. They have a reduced calculation time. Sometimes, just one iteration is necessary to reach the result [10].

Explicit modeling from current and voltage characteristic is used by [13] where from a single diode model, a Pade's approximate method is used to extract the parameters. In [14], Lambert W-function is used to extract parameters. In [15], the author used Taylor's series expansion to extract the five parameters in the single diode model. [16] developed a sample model to extract just four parameters without shunt resistance. In [17], analytical methods are compared with a curve-fitting tool method, and the result shows that the analytic method is more accurate. Analytical methods work properly under standard weather conditions; but when 
weather conditions change, analytical methods become ineffective [18].

Numerical extraction techniques based on some algorithm fit the points on the PV characteristic curve. Compared to the analytical method, an accurate result can be attained since the algorithm tries to consider all points on the characteristic curve [19]. In the literature, the Newton-Raphson method is the most used [19] [20] [21]; In [22], a numerical method is proposed for modeling and the simulation of PV. The method finds the five parameters from the current-voltage characteristic by using three points of the curve (maximum power, open circuit and short circuit). In [23], the Levenberg Marquardt algorithm is implemented to estimate the parameters from the I-V characteristic of a single diode PV model.

The main drawbacks of numerical techniques such as Newton Raphson are the need for extensive computations for convergence and fail to result in accurate results when the number of parameters to be estimated increases and a close approximation of initial conditions [24].

Despite the efficiency of the numerical methods, their slow convergence does not always guarantee the best result because they can converge through a local minimum and the choice of the initial condition is not often easy [11].

To overcome the drawback of analytical and iterative methods, metaheuristic algorithms have been developed. They are nature-inspired algorithms using probabilities to find the best result. They have shown their effectiveness in solving difficult problems. Their main advantage is that they do not need continuity and differentiability of the objective function In the last decade, metaheuristics have been frequently applied for parameter estimation of circuit model parameters of solar PV cells. The main develops in recent research are: genetic algorithm (GA) [25], grey wolf optimization (GWO) [26], particles swarm optimization (PSO) [27], moth-flame optimization algorithm (MFOA) [28], harmony search (HS) [29], artificial neural network (ANN) [30], multi-verse optimizer (MVO) [31], bond-graph based modelling [32], cuckoo search (CS) [33], bacterial foraging optimization [34], multiple learning backtracking search algorithm (MLBSA) [35], whale optimization algorithm (WAO) [36], salp swarm-inspired algorithm (SSA) [37]... New metaheuristic algorithms have been also recently developed to solve mathematic and engineering problems. [38] used World Cup Optimization (WCO) algorithm to find the optimal parameters of PID controller; in [39] a new algorithm based on Variance Reduction of Guassian Distribution is proposed; a new algorithm based on the invasive weed by the quantum computing is proposed by [40]; [41] combined Gravitational Search Algorithm (GSA) and Particle Swarm Optimization (PSO) to train wavelet neural networks.

Until today in the research and industry domain, there is no method of extracting PV parameter that has been introduced in the manufacturing of PV. By another, "The no-free-lunch theorem" remarked that: there is no algorithm able to solve all optimization problems, where it is important to propose new algorithms for solving engineering optimization problems [42]. In this paper, a new algorithm based on EVPS is used to extract parameters from a PV system. The 
inspiration of vibrating particles system comes from the free vibration of one degree of freedom systems with viscous damping. The algorithm has been applied to extract the best parameters of a PV cell and module under uniform and partial shading conditions. Five recent algorithms (SSA [37], GWO, MFOA [28], WAO [36], MVO [31]) are also implemented on the same computer with the parameters gave by authors. The result obtained from the EVPS is compared with other recent methods in the literature and different results obtain to demonstrate the high quality of the algorithm.

The rest of this paper is presented as follows: In Section 2, PV cell modeling is presented; Section 3 presents the problem formulation for extracting parameters from single and double diode model; the inspiration and the mathematical model of vibrating particles system are proposed in Section 4; Section 5 presents the different case study with different results and Section 6 is the conclusion.

\section{Photovoltaic Cell Modeling}

Many models of PV cell have been developed in the literature; but there are two models mostly used: single and double diode model.

\subsection{Single Diode Model}

Most of the literature uses this model. The main reason for this widely used is their simplicity and the least number of parameters. In the single diode model, there are five parameters to be extracted. Figure 1 shows the electric diagram of the model.

The current I at the output of a PV module can be expressed using Kirchhoff s theorem in Equation (1).

$$
I=I_{r}-I_{d}-I_{p}
$$

The diode current can be express as:

$$
I_{d}=I_{0}\left[\exp \left(\frac{V_{d}}{n \cdot V_{t}}\right)-1\right]
$$

where

$$
V_{t}=\frac{N_{s} \cdot K \cdot T}{q}
$$

The current through parallel resistance is

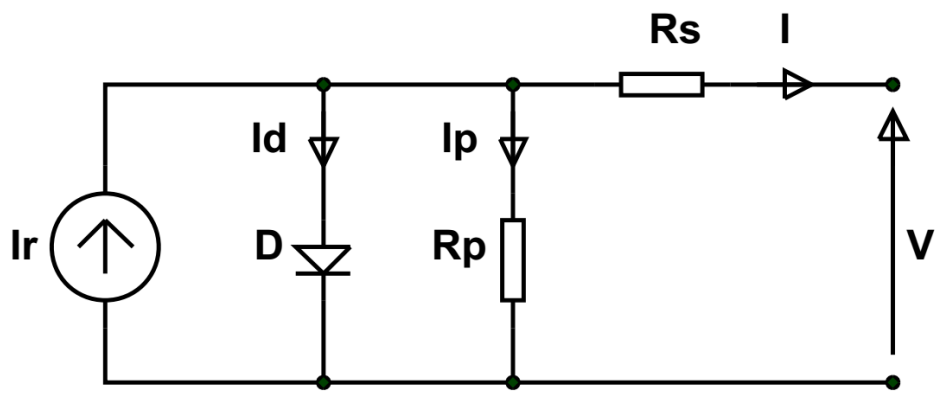

Figure 1. Electrical diagram of one diode PV cell. 


$$
I_{p}=\frac{V+I \cdot R_{s}}{R_{p}}
$$

By replacing Equation (2) \& Equation (3) into Equation (1), we have the output current at the output of a PV module.

$$
I=I_{r}-I_{0}\left[\exp \left(\frac{V_{d}}{n \cdot V_{t}}\right)-1\right]-\frac{V+I \cdot R_{s}}{R_{p}}
$$

The parameters which characterize this equation are: $\theta=\left[I_{r}, I_{0}, n, R_{s}, R_{p}\right]$. These five parameters can be determined by all the method described in Section 1.

\subsection{Double Diode Model}

This double-diode model (Figure 2) has a better accuracy than one diode model, but also more complex because of the numbers of parameters [11]. The model has been used by many authors [11] [43] [44] [45].

The current I, at the output of a PV module can be expressed using Kirchhoff's theorem in Equation (6).

$$
I=I_{r}-I_{d 1}-I_{d 2}-I_{p}
$$

The diodes currents can be express as:

$$
\begin{gathered}
I_{d 1}=I_{01}\left[\exp \left(\frac{V_{d}}{n_{1} \cdot V_{t}}\right)-1\right] \\
I_{d 2}=I_{02}\left[\exp \left(\frac{V_{d}}{n_{2} \cdot V_{t}}\right)-1\right]
\end{gathered}
$$

where

$$
V_{t}=\frac{N_{s} \cdot K \cdot T}{q}
$$

The current through parallel resistance is

$$
I_{p}=\frac{V+I \cdot R_{s}}{R_{p}}
$$

By replacing Equations (7)-(10) into Equation (6), we have the output current at the output of a PV module:

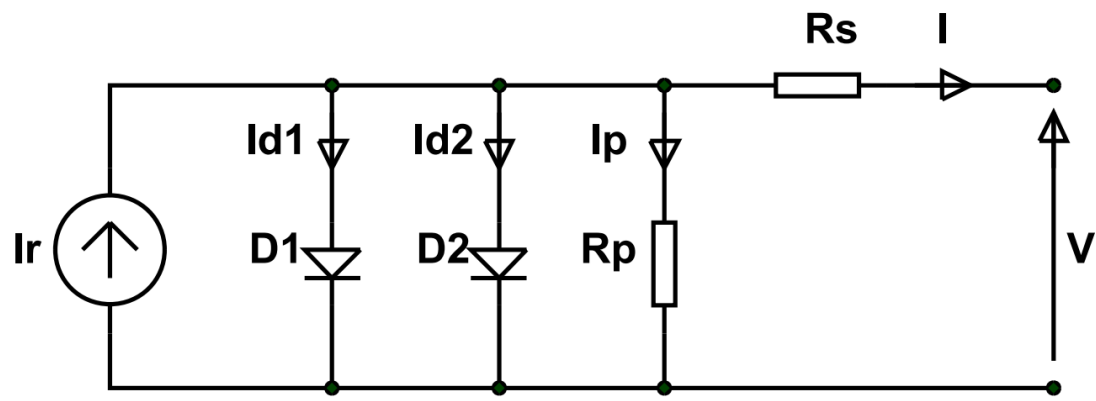

Figure 2. Electrical diagram of double diode PV cell. 


$$
I=I_{r}-I_{01}\left[\exp \left(\frac{V_{d}}{n_{1} \cdot V_{t}}\right)-1\right]-I_{02}\left[\exp \left(\frac{V_{d}}{n_{2} \cdot V_{t}}\right)-1\right]-\frac{V+I \cdot R_{s}}{R_{p}}
$$

The parameters which characterize this equation are:

$$
\theta=\left[I_{r}, I_{01}, I_{02}, n_{1}, n_{2}, R_{s}, R_{p}\right] .
$$

These seven parameters can be determined by all the methods described in Section 1 .

\section{Problem Formulation}

To extract the PV parameters using EVPS, the problem can be set as an optimization problem with the objective to minimize the difference between measured and estimated current. The objective function (OF) is defined as the root mean square error (RMSE) where the error function is defined as the difference between estimated and experimental currents. It's expressed as follows:

$$
\operatorname{Min}(F(\theta))=\sqrt{\frac{1}{N} \sum_{i=1}^{N}\left(I_{i, m e s}-I_{i, e x t}(\theta)\right)^{2}}
$$

where:

$F(\theta)$ : is the objective function to minimize;

$N$ : is the number of points $\left(V_{i}, I_{i}\right)$ measured;

$I_{i, m e s}:$ is the measured current;

$I_{\text {iext }}(\theta):$ is the estimated current;

$\theta=\left[I_{r}, I_{01}, I_{02}, n_{1}, n_{2}, R_{s}, R_{p}\right]:$ Parameters to estimate.

For a single diode model, the objective function is expressed as:

$$
\operatorname{Min}(F(\theta))=\sqrt{\frac{1}{N} \sum_{i=1}^{N}\left(I_{i, m e s}-I_{r}+I_{0}\left[\exp \left(\frac{V_{i, m e s}+I_{i, \text { mes }} \cdot R_{s}}{n \cdot V_{t}}\right)-1\right]+\frac{V_{i, \text { mes }}+I_{i, \text { mes }} \cdot R_{s}}{R_{p}}\right)^{2}}
$$

with $\theta=\left[I_{r}, I_{0}, n, R_{s}, R_{p}\right]$ the parameters to estimate.

For double diode model, the objective function is:

$$
\operatorname{Min}(F(\theta))=\sqrt{\frac{1}{N} \sum_{i=1}^{N}\left(I_{i, m e s}-I_{r}+I_{01}\left[\exp \left(\frac{V_{i, m e s}+I_{i, m e s} \cdot R_{s}}{n_{1} \cdot V_{t}}\right)-1\right]+I_{02}\left[\exp \left(\frac{V_{i, m e s}+I_{i, m e s} \cdot R_{s}}{n_{2} \cdot V_{t}}\right)-1\right]+\frac{V_{i, m e s}+I_{i, m e s} \cdot R_{s}}{R_{p}}\right)^{2}}
$$

with $\theta=\left[I_{r}, I_{01}, I_{02}, n_{1}, n_{2}, R_{s}, R_{p}\right]$ the parameters to estimate

In this paper, EVPS algorithm is used to minimize Equation (13) and Equation (14).

\section{Optimization Algorithm}

\subsection{Inspiration}

The inspiration of vibrating particles system comes from the free vibration of a single degree of freedom system with viscous damping. The VPS contains a number of population solutions that represent the particle system. The particles are randomly initialized in an $n$-dimensional search space and step-by-step, they 
approach their equilibrium positions [46].

\subsection{The Vibrating Particles System Algorithm}

As other meta-heuristic algorithms, VPS has population particles which are considered as the parameters of the problem. The initial positions of particles are firstly generated randomly.

$$
x_{j}^{i}=x_{\text {min }}-\operatorname{rand}\left(x_{\text {max }}-x_{\text {min }}\right)
$$

$x_{j}^{i}$ represents the $j$ th position of the ith particle; $x_{\min }$ and $x_{\max }$ are respectively the initial and the final position rand is a random number between $[0$, $1]$.

Three equilibrium positions affected by different weights are defined for each particle. During each generation, the particle positions are updated by learning from them. The equilibrium positions are:

- HB: Historically best location;

- GP: Good particle;

- BP: Bad particle.

To include the effect of the damping level in the vibration, a descending function is introduced:

$$
D=\left(\frac{i t e r}{i t e r_{\max }}\right)^{-\alpha}
$$

iter, $_{\text {iter }}{ }_{\max }$ and $\alpha$ : represent respectively the current iteration, the maximum iteration and a constant.

The next position is updated by the following equations:

$$
\begin{aligned}
& x_{j}^{i}= w_{1}\left[D \cdot A \cdot \text { rand }_{1}+H B^{j}\right]+w_{2}\left[D \cdot A \cdot \text { rand }_{2}+G P^{j}\right] \\
&+w_{3}\left[D \cdot A \cdot \text { rand }_{3}+B P^{j}\right] \\
& A= {\left[W_{1}\left(H B^{j}-x_{i}^{j}\right)\right]+\left[W_{2}\left(G P^{j}-x_{i}^{j}\right)\right]+\left[W_{3}\left(B P^{j}-x_{i}^{j}\right)\right] } \\
& W_{1}+W_{2}+W_{3}=1
\end{aligned}
$$

$x_{j}^{i}$ : represent the ${ }^{\text {th }}$ position of the $i$ th particle;

$W_{1}, W_{2}, W_{3}$ : parameters to measure the best value of $\mathrm{HB}, \mathrm{GP}, \mathrm{BP}$;

rand $_{1}$, rand $_{2}$, rand $_{3}$ : random numbers between $[0,1]$.

\subsection{Enhanced Vibrating Particles System Algorithm}

\subsubsection{Description}

EVPS algorithm has been initially developed by [47]; the main advantages of EVPS are to avoid slow convergence, local minimum and increase the number of space search.

In EVPS, we introduced two new parameters: "memory" and "OHB (one of the best historically locations in the whole population)" [47]. HB in VPS is replaced by the memory. The memory now saves the best historically positions of the whole population. OHB is one row of memory whose selection is random. The next changing is the replacement of Equation (17) by Equation (18). 


$$
\begin{aligned}
& x_{j}^{i}=\left\{\begin{array}{l}
{\left[D \cdot A \cdot \text { rand }_{1}+O H B^{j}\right]} \\
{\left[D \cdot A \cdot \text { rand }_{2}+G P^{j}\right]} \\
{\left[D \cdot A \cdot \text { rand }_{3}+B P^{j}\right]}
\end{array}\right. \\
& A=\left\{\begin{array}{l}
( \pm 1)\left(O H B^{j}-x_{i}^{j}\right) \\
( \pm 1)\left(G P^{j}-x_{i}^{j}\right) \\
( \pm 1)\left(B P^{j}-x_{i}^{j}\right)
\end{array}\right. \\
& W_{1}+W_{2}+W_{3}=1
\end{aligned}
$$

$( \pm 1)$ are applied randomly. BP, GP and OHB are independently determined for each particle [47]. All details concerning VPS algorithm can be found in [47].

\subsubsection{Details Algorithms}

The steps to compute EVPS algorithms are described as follows:

Step 1: Initializing of EVPS's parameters.

- Initialize VPS parameters (size of the population, number of optimization variables, memory size, maximum number of iterations, lower and upper bound of the variables, parameters for handling the side constraints, $w_{1}$ and $\left.w_{2}\right)$.

- Initializing particles positions using Equation (19).

$$
x_{j}^{i}=x_{\min }-\operatorname{rand}\left(x_{\max }-x_{\min }\right)
$$

Step 2: Search.

- Evaluate the objective function for each particle.

- For each particle, select "memory" and "OHB (one of the best historically locations in the whole population).

- Update particle's position.

$$
D=\left(\frac{i t e r}{i t e r_{\max }}\right)^{-\alpha}
$$

Updating the next position by

$$
\begin{aligned}
& x_{j}^{i}=\left\{\begin{array}{l}
{\left[D \cdot A \cdot \text { rand }_{1}+O H B^{j}\right]} \\
{\left[D \cdot A \cdot \text { rand }_{2}+G P^{j}\right]} \\
{\left[D \cdot A \cdot \text { rand }_{3}+B P^{j}\right]}
\end{array}\right. \\
& A=\left\{\begin{array}{l}
( \pm 1)\left(O H B^{j}-x_{i}^{j}\right) \\
( \pm 1)\left(G P^{j}-x_{i}^{j}\right) \\
( \pm 1)\left(B P^{j}-x_{i}^{j}\right)
\end{array}\right. \\
& W_{1}+W_{2}+W_{3}=1
\end{aligned}
$$

A parameter like $k$ in a range of $[0,1]$ must be defined to specify if BP must be considered in the new position. For each population, $k$ is compared with a random number (rand) uniformly distributed in the range of $[0,1]$; if $k<$ rand, then 
$W_{3}=0$ and $w_{1}=1-w_{2}$.

Step 3: Handling the Side Constraints.

If a particle went out of the boundary, it must be updated by harmony search-based side constraints handling approach. The method consists to determine if the violating particle should be updated either by the best historically particle or randomly in the search space.

Step 4: Out memory and best positions.

\subsection{Application of Enhanced Vibrating Particles System to Photovoltaic Parameters Extraction}

\subsubsection{Problem Statement}

The goal is to determine the global optimum, which is the best value of the OF (RMSE). If we replace memory (OHB) by the global optimum and the positions $\left(x_{j}^{i}\right)$ by the estimated parameters, therefore $\left(\theta_{i}\right)$, the best position automatically moves towards it. However, the problem is that the global solution of the optimization problems is unknown. In this case, the optimal solution obtained is the global optimum and presumed as the best selection of the memory.

\subsubsection{Problem Formulation}

The objective function of Equation (22) is used to find the best parameters of single and double diode model; the difference between single and double diodes model is the numbers of parameters ( 5 to single diode model and 7 to double diodes model). The formulation is:

$$
\begin{aligned}
& \text { Find } \triangleright\{x\}=\left[x_{1}, x_{2}, x_{3}, \cdots, x_{N}\right] \\
& \text { To minimize } F(x)=\sqrt{\frac{1}{N} \sum_{i=1}^{N}\left(I_{i, \text { mes }}-I_{i, \text { ext }}(x)\right)^{2}} \\
& \text { Subjected to }\left\{\begin{array}{l}
g_{j}(\{x\}) \leq 0, j=1,2,3, \cdots, N c \\
x_{i_{\min }} \leq x_{i} \leq x_{i_{\max }}
\end{array}\right.
\end{aligned}
$$

where $[x]$ is the best parameters; $n g$ is the number of parameters; $F(x)$ the RMSE; $N$ the number of points $\left(V_{i}, I_{i}\right)$ measured; $I_{i, \text { mes }}$ the measured current; $I_{i, e x t}(x)$ the estimated current; $x_{i_{\min }}$ is the lower bound, and $x_{i_{\max }}$ the upper bounds; $g_{j}(\{x\})$ the design constraints and $N c$ the number of constraints.

The objective function of each model is formulated as follows:

\section{- Single diode model}

For a single diode model, the objective function is expressed as:

$$
\operatorname{Min}(F(x))=\sqrt{\frac{1}{N} \sum_{i=1}^{N}\left(I_{i, \text { mes }}-x_{1}+x_{2}\left[\exp \left(\frac{V_{i, m e s}+I_{i, m e s} \cdot x_{4}}{x_{3} \cdot V_{t}}\right)-1\right]+\frac{V_{i, \text { mes }}+I_{i, \text { mes }} \cdot x_{4}}{x_{5}}\right)^{2}}
$$

Subjected to: $x_{i_{\min }} \leq x_{i} \leq x_{i_{\max }}$

with $x=\left[x_{1}, x_{2}, x_{3}, x_{4}, x_{5}\right]$ the five estimated parameters which correspond respectively to $\theta=\left[I_{r}, I_{0}, n, R_{s}, R_{p}\right]$.

\section{- Double diode model}

For single diode model, the objective function is expressed as: 
$\operatorname{Min}(F(\theta))=\sqrt{\frac{1}{N} \sum_{i=1}^{N}\left(I_{i, \text { mes }}-x_{1}+x_{2}\left[\exp \left(\frac{V_{i, \text { mes }}+I_{i, \text { mes }} \cdot x_{6}}{x_{4} \cdot V_{t}}\right)-1\right]+x_{3}\left[\exp \left(\frac{V_{i, \text { mes }}+I_{i, \text { mes }} \cdot x_{6}}{x_{5} \cdot V_{t}}\right)-1\right]+\frac{V_{i, \text { mes }}+I_{i, \text { mes }} \cdot x_{6}}{x_{7}}\right)^{2}}$

Subjected to : $x_{i_{\min }} \leq x_{i} \leq x_{i_{\max }}$

with $x=\left[x_{1}, x_{2}, x_{3}, x_{4}, x_{5}, x_{6}, x_{7}\right]$ the seven estimated parameters which correspond respectively to $\theta=\left[I_{r}, I_{01}, I_{02}, n_{1}, n_{2}, R_{s}, R_{p}\right]$.

The flowchart algorithm is represented in Figure 3.

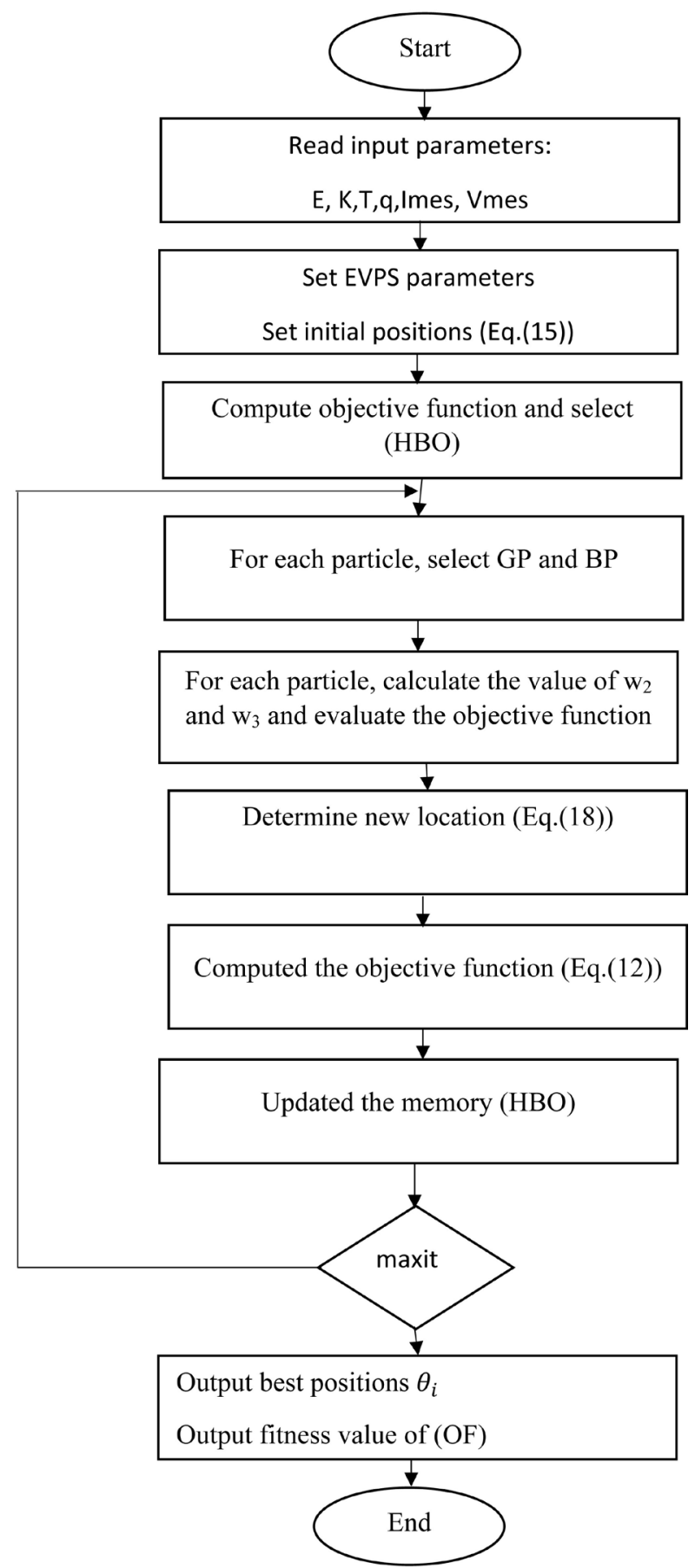

Figure 3. Flowchart of the EVPS algorithm. 


\section{Experiment and Results}

This section presents different results and implementation of the algorithm. Four case studies have been implemented. The first two cases of study have been implemented in Matlab 2017a. In the first case study; Photowatt-PWP201 PV which has 36 polycrystalline silicon cells, all connected in series, the irradiance is $1000 \mathrm{~W} / \mathrm{m}^{2}$ and temperature $45^{\circ} \mathrm{C}$. The second case refers to the RTC France commercial silicon PV, irradiance is $1000 \mathrm{~W} / \mathrm{m}^{2}$ and temperature $33^{\circ} \mathrm{C}$. These two cases were for the first time initiated by [48] and it's largely used today in research as a test system. To show the performance of the algorithm, a Matlab-Simulink model has been implemented in different irradiance conditions. The third case refers to polycrystalline SW255. The fourth case implements real experimental data from the Sharp ND-R250A5 PV module provided to us by [11].

\subsection{Case Study 1}

A single diode model has been implemented in this case study to extract the five parameters of the Photowatt-PWP201 PV which is a $11.5 \mathrm{~W}$ PV module. It has 36 cells connected in series. Irradiance is $1000 \mathrm{~W} / \mathrm{m}^{2}$ and temperature $45^{\circ} \mathrm{C}$. It's widely used in literature by many researchers. The manufacturer's characteristics of the PV module at STC are listed in Table 1 and the lower and upper bound are expressed in Table 2. The $26 \mathrm{I}-\mathrm{V}$ measured data has been collected from [35] [11]. Five recent algorithms (SSA, GWO, MFOA, WAO and MVO) are also implemented in this case study in order to make the comparison. The initial parameters of each algorithm are given by the authors in each paper.

The initial parameters of EVPS are: number of search agents $=50$; maximum number of iterations $=1000 ;$ alpha $=0.05 ; w_{1}=0.3 ; w_{2}=0.3$.

\subsection{Result of Case Study 1}

Table 3 presents the result of the five estimated parameters of the Photowatt-PWP201 PV module and the best OF (RMSE) after 20 independent tests is $2.4267 \times 10^{-3}$. In Table 4 the results of the 5 other algorithms are presented. The Average value of RMSE shows the constant of the algorithm after many tests. The comparison with other methods in the literature is presented in Table 5 to

Table 1. PWP201 PV module parameter.

\begin{tabular}{cc}
\hline Parameters & Values \\
\hline$I_{s c}(\mathrm{~A})$ & 1.0317 \\
$V_{o c}(\mathrm{~V})$ & 16.7785 \\
$I_{m p}(\mathrm{~A})$ & 0.9120 \\
$V_{m p}(\mathrm{~V})$ & 12.6490 \\
$N_{s}$ & 36 \\
$K_{i}$ for $I_{s c}$ & $0.0360 \% / \mathrm{C}$ \\
\hline
\end{tabular}


Table 2. Lower and upper bound.

\begin{tabular}{ccc}
\hline Parameters & Lower Bound & Upper Bound \\
\hline$I_{r}(\mathrm{~A})$ & 0 & 10 \\
$I_{o}(\mathrm{~A})$ & $1 \mathrm{e}-12$ & $1 \mathrm{e}-5$ \\
$n$ & 0.5 & 2.5 \\
$R_{s}(\Omega)$ & 0.001 & 2 \\
$R_{p}(\Omega)$ & 0.001 & 5000 \\
\hline
\end{tabular}

Table 3. Best result for case study 1 .

\begin{tabular}{cc}
\hline Parameters & Best Solutions \\
\hline$I_{r}(\mathrm{~A})$ & 1.0318 \\
$I_{o}(\mathrm{~A})$ & 3.2679 \\
$n$ & 1.3445 \\
$R_{s}(\Omega)$ & 1.2066 \\
$R_{p}(\Omega)$ & 845.759 \\
OF (RMSE) & $2.4267 \times 10^{-3}$ \\
\hline
\end{tabular}

Table 4. Comparison results of five algorithms for 20 independent tests.

\begin{tabular}{cccccccc}
\hline \multirow{5}{*}{ Best } & Parameters & WOA [36] & SSA [37] & MVO [31] & GWO [26] & MFO [28] & EVPS \\
\cline { 2 - 7 } & $I_{r}(\mathrm{~A})$ & 1.0320 & 1.0452 & 1.0329 & 1.0324 & 1.0325 & 1.0318 \\
& $I_{o}(\mu \mathrm{A})$ & 7.5936 & 4.7508 & 1.7849 & 4.6572 & 2.7228 & 3.2695 \\
& $n$ & 1.4414 & 1.3868 & 1.2833 & 1.3832 & 1.3254 & 1.3446 \\
& $R_{s}(\Omega)$ & 1.0444 & 1.0950 & 1.2775 & 1.1354 & 1.2255 & 1.2064 \\
& $R_{p}(\Omega)$ & 738.6218 & 406.5791 & 658.9906 & 820.9687 & 742.2522 & 843.7385 \\
& $\mathrm{RMSE} \times 10^{-3}$ & 6.3860 & 7.6817 & 3.1162 & 3.9851 & 2.4842 & 2.4267 \\
\hline \multirow{6}{*}{ Worst } & $I_{r}(\mathrm{~A})$ & 1.3568 & 0.9884 & 1.0489 & 1.0960 & 1.0856 & 1.0329 \\
& $I_{o}(\mu \mathrm{A})$ & 9.6098 & 8.6491 & 8.635 & 1.7016 & 6.0648 & 6.5761 \\
& $n$ & 1.5413 & 1.4705 & 1.4586 & 1.3057 & 1.4235 & 1.4231 \\
& $R_{s}(\Omega)$ & 0.2965 & 0.1955 & 1.0475 & 0.2845 & 0.8900 & 1.1183 \\
& $R_{p}(\Omega)$ & 23.0796 & 549.0804 & 337.8831 & 61.4542 & 118.6442 & 999.5245 \\
& $\mathrm{RMSE} \times 10^{-3}$ & 141.6485 & 71.9332 & 9.0679 & 67.7101 & 24.9788 & 3.4707 \\
\hline Average & $\mathrm{RMSE} \times 10^{-3}$ & 44.1232 & 28.2501 & 5.4726 & 19.0572 & 3.9637 & 2.7877 \\
\hline
\end{tabular}

Table 5. Comparison of the results obtained from the Photowatt-PWP201 PV with other methods in the literature.

\begin{tabular}{cccccccccc}
\hline Parameters & TVAPSO [49] & LI [50] & IADE [51] & PS [52] & SA [43] & RF [53] & GCPSO [11] & GAMS [56] & EVPS \\
\hline$I_{r}(\mathrm{~A})$ & 1.031435 & 1.0334 & 1.0311 & 1.0313 & 1.0331 & 1.032375 & 1.0323823 & 1.032015 & 1.0318 \\
$I_{o}(\mu \mathrm{A})$ & 2.638610 & 2.4424 & 3.6642 & 3.1756 & 3.6642 & 2.518884 & 2.512922 & 3.26812 & 3.2679 \\
$n$ & 47.556652 & 1.2975 & 1.3561 & 1.3413 & 48.8211 & 1.239018 & 1.31730 & 1.344574 & 1.3445 \\
$R_{s}(\Omega)$ & 1.235611 & 1.2975 & 1.1989 & 1.2053 & 1.1989 & 1.317400 & 1.239288 & 1.206210 & 1.2066 \\
$R_{p}(\Omega)$ & 821.59514 & 603.4037 & 921.85 & 714,285 & 833.3333 & 745.6431 & 744.7166 & 828.292864 & 845.759 \\
$\mathrm{RMSE} \times 10^{-3}$ & 6.9665 & 2.477 & 2.4 & 11.8 & 2.7 & 2.7001 & 2.5915 & 2.442689 & 2.4267 \\
\hline
\end{tabular}


show the superiority of the algorithm. Figure 4 shows the I-V characteristics of the measured and estimated curve of the Photowatt-PWP201 PV under a 1000 $\mathrm{W} / \mathrm{m}^{2}$ irradiance and $45^{\circ} \mathrm{C}$ temperature. In Figure 5, the P-V characteristic of the measured and estimated curve is presented. Figure 6 presents the convergence of each algorithm.

\subsection{Case Study 2}

In this case, seven parameters of RTC France PV have been extracted. The irradiance of the RTC France PV is $1000 \mathrm{~W} / \mathrm{m}^{2}$ and temperature $33^{\circ} \mathrm{C}$. The typical electrical characteristics of the PV cell at STC are listed in Table 6; the lower and upper bound are expressed in Table 7. The $26 \mathrm{I}-\mathrm{V}$ measured data have been collected from [11]. The initial parameters of EVPS are the same as in case study 1.

\subsection{Result of Case Study 2}

Table 8 presents the result of the seven estimated parameters of the PV cell; the best OF (RMSE) after 20 tests is $9.8510 \mathrm{e}-4$. In Table 9 , the results of the 5 other algorithms are presented. In Table 10, the comparison with other methods in the literature is presented to show the superiority of the algorithm. Figure 7 shows the I-V characteristic of the measured and estimated curve of the PV cell under a $1000 \mathrm{~W} / \mathrm{m}^{2}$ and $33^{\circ} \mathrm{C}$. In Figure 8, the P-V characteristic of the measured and estimated curve is presented.

\subsection{Case Study 3}

The case study 3 consists of the implementation of a Matlab/Simulink model at

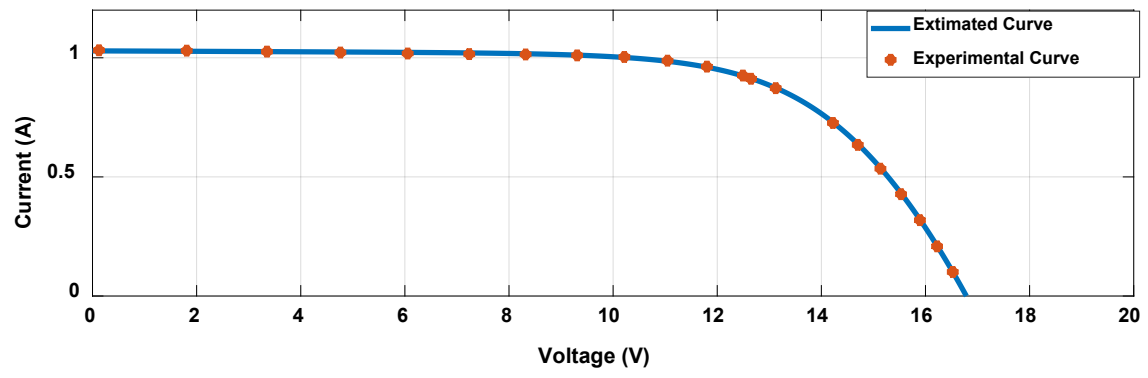

Figure 4. I-V characteristic of the measured and estimated curve.

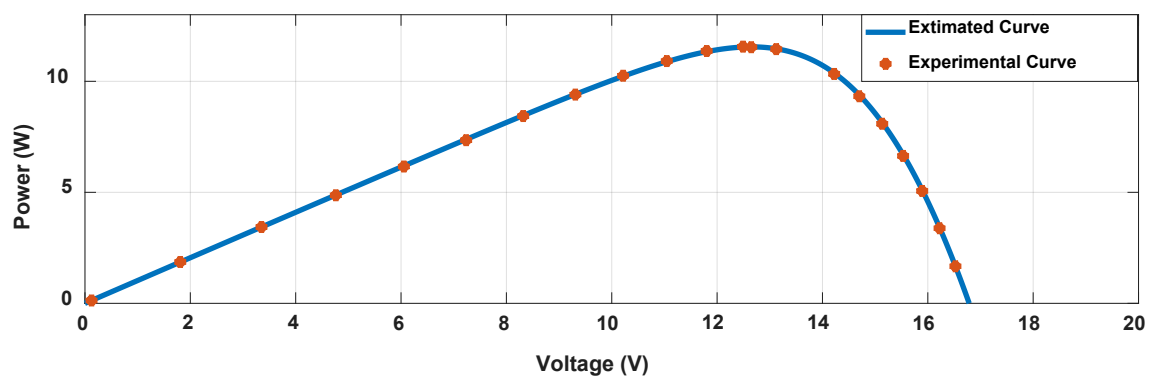

Figure 5. P-V characteristic of the measured and estimated curve. 
Table 6. RTC France cell parameter.

\begin{tabular}{cc}
\hline Parameters & Values \\
\hline$I_{s c}(\mathrm{~A})$ & 0.760 \\
$V_{o c}(\mathrm{~V})$ & 0.573 \\
$I_{m p}(\mathrm{~A})$ & 0.691 \\
$V_{m p}(\mathrm{~V})$ & 0.450 \\
$N_{s}$ & 1 \\
$K_{i}$ for $I_{s c}$ & $0.0350 \% / \mathrm{C}$ \\
\hline
\end{tabular}

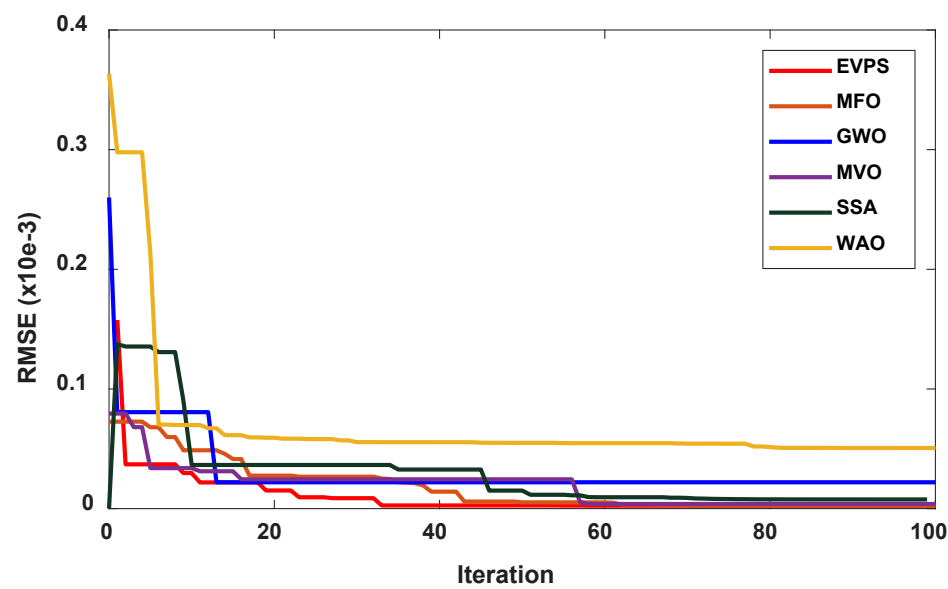

Figure 6. Comparaison of convergence curve.

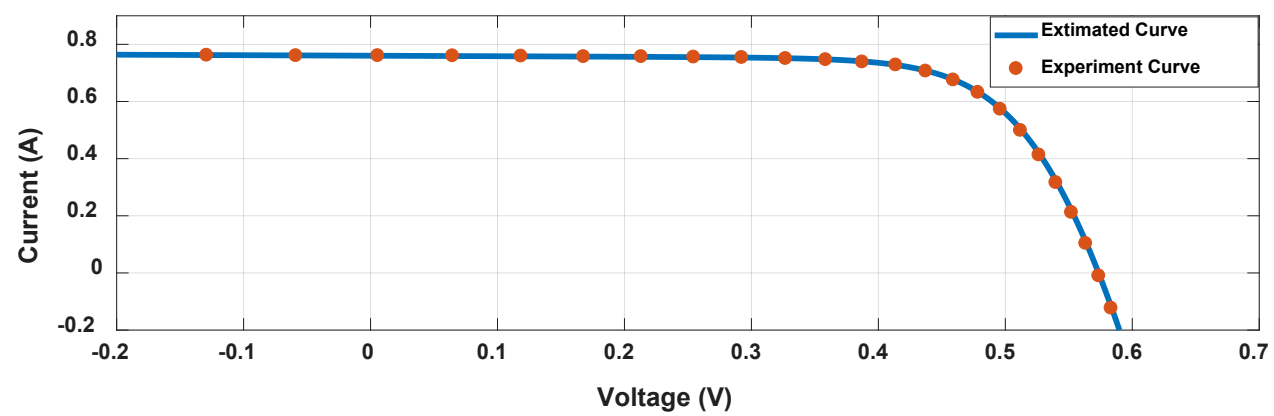

Figure 7. I-V characteristic of the measured and estimated curve.

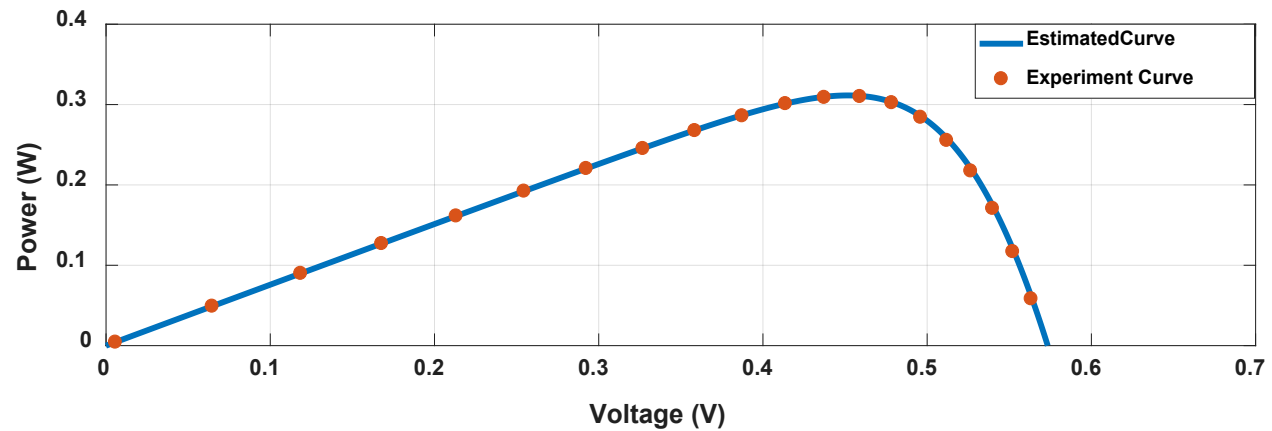

Figure 8. P-V characteristic of the measured and estimated curve. 
Table 7. Lower and upper bound.

\begin{tabular}{ccc}
\hline Parameters & Lower Bound & Upper Bound \\
\hline$I_{r}(\mathrm{~A})$ & 0 & 10 \\
$I_{o 1}(\mathrm{~A})$ & $1 \mathrm{e}-12$ & $1 \mathrm{e}-5$ \\
$I_{o 2}(\mathrm{~A})$ & $1 \mathrm{e}-12$ & $1 \mathrm{e}-5$ \\
$n_{1}$ & 0.5 & 2.5 \\
$n_{2}$ & 0.5 & 2.5 \\
$R_{s}(\Omega)$ & 0.001 & 2 \\
$R_{p}(\Omega)$ & 0.001 & 5000 \\
\hline
\end{tabular}

Table 8. Result for case study 2.

\begin{tabular}{cc}
\hline Parameters & Best Solutions \\
\hline$I_{r}(\mathrm{~A})$ & 0.7607 \\
$I_{o 1}(\mu \mathrm{A})$ & 0.29749 \\
$I_{o 2}(\mu \mathrm{A})$ & 0.2504 \\
$n_{1}$ & 1.4749 \\
$n_{2}$ & 1.9726 \\
$R_{s}(\Omega)$ & 0.0363 \\
$R_{p}(\Omega)$ & 55.8827 \\
OF $(\mathrm{RMSE})$ & $9.8510 \mathrm{e}-4$ \\
\hline
\end{tabular}

Table 9. Comparison results of five algorithms from the RTC France for 20 independent tests.

\begin{tabular}{|c|c|c|c|c|c|c|c|}
\hline \multirow{9}{*}{ Best } & Parameters & WOA [36] & SSA [37] & MVO [31] & GWO [26] & MFO [28] & EVPS \\
\hline & $I_{r}(\mathrm{~A})$ & 0.7646 & 0.7637 & 0.7606 & 0.7635 & 0.7627 & 0.7607 \\
\hline & $I_{o 1}(\mu \mathrm{A})$ & 1.7641 & 0.9880 & 3.6662 & 0.3639 & 0.0009 & 0.2975 \\
\hline & $I_{o 2}(\mu \mathrm{A})$ & 2.0948 & 0.8796 & 0.1880 & 0.0012 & 3.2555 & 0.2504 \\
\hline & $n_{1}$ & 1.6839 & 2.2119 & 2.1225 & 1.4942 & 1.1596 & 1.4749 \\
\hline & $n_{2}$ & 2.1583 & 1.5932 & 1.4417 & 2.1433 & 1.7848 & 1.9726 \\
\hline & $R_{s}(\Omega)$ & 0.0277 & 0.0307 & 0.0354 & 0.0348 & 0.0293 & 0.0363 \\
\hline & $R_{p}(\Omega)$ & 64.2652 & 42.7318 & 94.5515 & 30.7060 & 100.0000 & 55.8827 \\
\hline & $\mathrm{RMSE} \times 10^{-3}$ & 53.6880 & 35.4087 & 14.8497 & 26.2566 & 45.8807 & 9.8510 \\
\hline \multirow{8}{*}{ Worst } & $I_{r}(\mathrm{~A})$ & 0.7457 & 0.7765 & 0.7756 & 0.7669 & 0.7589 & 0.7606 \\
\hline & $I_{o 1}(\mu \mathrm{A})$ & 2.5483 & 3.2039 & 4.5604 & 0.9919 & 10.0000 & $1.262 \mathrm{e}-03$ \\
\hline & $I_{o 2}(\mu \mathrm{A})$ & 3.2766 & 5.8725 & 0.9121 & 9.9708 & 10.0000 & 0.5005 \\
\hline & $n_{1}$ & 1.7422 & 2.0224 & 1.8147 & 2.0889 & 2.1160 & 1.2067 \\
\hline & $n_{2}$ & 2.2150 & 1.8891 & 2.4204 & 1.9505 & 2.0254 & 1.5392 \\
\hline & $R_{s}(\Omega)$ & 0.0014 & 0.0135 & 0.0181 & 0.0015 & 0.0010 & 0.0358 \\
\hline & $R_{p}(\Omega)$ & 87.5855 & 13.7374 & 13.8209 & 15.8790 & 100.0000 & 63.4186 \\
\hline & $\mathrm{RMSE} \times 10^{-3}$ & 322.0510 & 150.5212 & 135.4657 & 200.7120 & 166.5394 & 11.19 \\
\hline Average & $\mathrm{RMSE} \times 10^{-3}$ & 164.3665 & 82.9360 & 93.3376 & 107.7185 & 86.5089 & 10.083 \\
\hline
\end{tabular}


Table 10. Comparison of the RTC France PV obtained results with the ones in the literature.

\begin{tabular}{ccccccccc}
\hline \multicolumn{2}{c}{ Parameters } & MBA [45] SA [43] & HS [29] & CPSO [11] & ABCO [44] & ABC [55] & IGHS [29] & EVPS \\
\hline$I_{r}(\mathrm{~A})$ & 0.7605 & 0.7623 & 0.7616 & 0.762321 & 0.7608 & 0.7609 & 0.76079 & $\mathbf{0 . 7 6 0 7}$ \\
$I_{o 1}(\mu \mathrm{A})$ & 0.4513 & 0.4767 & 0.12546 & 0.297108 & 0.0407 & 2.6900 & 0.97310 & $\mathbf{0 . 2 9 7 4 9}$ \\
$I_{o 2}(\mu \mathrm{A})$ & 1.1846 & 0.0100 & 0.25470 & 0.710454 & 0.2874 & 2.8198 & 0.16791 & $\mathbf{0 . 2 5 0 4}$ \\
$n_{1}$ & 1.5920 & 1.517 & 1.49439 & 1.476035 & 1.4495 & 1.4670 & 1.92126 & $\mathbf{1 . 4 7 4 9}$ \\
$n_{2}$ & 1.8450 & 2.000 & 1.49989 & 1.998103 & 1.4885 & 1.8722 & 1.42814 & $\mathbf{1 . 9 7 2 6}$ \\
$R_{s}(\Omega)$ & 0.0314 & 0.0345 & 0.03562 & 0.035601 & 0.0364 & 0.0364 & 0.03690 & $\mathbf{0 . 0 3 6 3}$ \\
$R_{p}(\Omega)$ & 493.7200 & 43.10 & 46.8269 & 45.547533 & 53.7804 & 55.2307 & 56.8368 & $\mathbf{5 5 . 8 8 2 7}$ \\
$\mathrm{RMSE} \times 10^{-4}$ & 0.1092 & 0.01667 & 12.6 & 13.0565 & 9.861 & 10 & 9.8635 & $\mathbf{9 . 8 5 1 0}$ \\
\hline
\end{tabular}

different irradiance conditions. The case study 3 refers to the polycrystalline SW255. The using manufacturer data at STC is reported in Table 11 [54]. The Simulink model is presented in Figure 9. The block solar cell is configured with the STC condition of Table 11. The experiment data at each irradiance condition $\left(E\left(\mathrm{~W} / \mathrm{m}^{2}\right)=1000,800,600,400,200\right)$ at $25^{\circ} \mathrm{C}$ temperature are exported to Matlab via the blocks Workspace.

\subsection{Result of Case Study 3}

Table 12 and Table 13 present respectively the result of the five and seven estimated parameters of the polycrystalline SW255 module at different irradiance conditions. In Table 14, the results of the 5 other algorithms are presented. Figure 10 shows the I-V characteristic of the measured and estimated curve under different irradiance. In Figure 11, the P-V characteristic of the measured and estimated curve is presented.

\subsection{Case Study 4}

One diode model has been implemented in this last case to extract the five parameters based on experimental data of the Sharp ND-R250A5 PV module. The $\mathrm{PV}$ has 60 cells in series. Irradiance is $1040 \mathrm{~W} / \mathrm{m}^{2}$ and temperature $59^{\circ} \mathrm{C}$. The typical electrical characteristics of the Sharp ND-R250A5 PV module at STC are listed in Table 15 and the lower and upper bound are expressed in Table 16. The $36 \mathrm{I}-\mathrm{V}$ measured data has been provided to us by [11], where irradiance and temperature have been measured by the sensor Ingenieurbüro Si-13TC-T (Figure 12).

\subsection{Result of Case Study 4}

Table 17 presents the result of the five estimated parameters of the Sharp ND-R250A5 PV module. The best OF (RMSE) is $11.252719 \times 10^{-3}$. Figure 13 shows the I-V characteristics of the measured and estimated curve of the ND-R250A5 PV under a $1040 \mathrm{~W} / \mathrm{m}^{2}$ irradiance and $59^{\circ} \mathrm{C}$ temperature. In Figure 14 , the P-V characteristic of the measured and estimated curve is presented. Figure 15 presents the convergence curve. 
Table 11. Datasheet parameters of SW255 at STC.

\begin{tabular}{cc}
\hline Parameters & Values \\
\hline$I_{s c}(\mathrm{~A})$ & 8.8 \\
$V_{o c}(\mathrm{~V})$ & 38.0 \\
$I_{m p}(\mathrm{~A})$ & 8.32 \\
$V_{m p}(\mathrm{~V})$ & 30.9 \\
$P_{m p}(\mathrm{~W})$ & 255 \\
$N_{s}$ & 60 \\
$K_{i}[\mathrm{~A} / \mathrm{K}]$ & 0.051 \\
$K_{V}[\mathrm{~A} / \mathrm{K}]$ & -0.31 \\
\hline
\end{tabular}

Table 12. Five estimated parameters of the polycrystalline SW255 module at different irradiance conditions.

\begin{tabular}{cccccc}
\hline Parameters & 1000 & 800 & 600 & 400 & 200 \\
$\mathrm{E}\left(\mathrm{W} / \mathrm{m}^{2}\right)$ & 8.9005 & 7.1156 & 5.3376 & 3.5635 & 1.7760 \\
\hline$I_{r}(\mathrm{~A})$ & $2.376 \mathrm{e}-07$ & $6.8846 \mathrm{e}-08$ & $6.8962 \mathrm{e}-08$ & $6.8596 \mathrm{e}-08$ & $6.8830 \mathrm{e}-08$ \\
$I_{o}(\mathrm{~A})$ & 1.3632 & 1.3212 & 1.3222 & 1.3232 & 1.3264 \\
$n$ & 0.2109 & 0.2169 & 0.2110 & 0.1937 & 0.1942 \\
$R_{s}(\Omega)$ & 6709.6 & 4428.5 & 6065 & 2177.7 & 2742.4 \\
$R_{p}(\Omega)$ & 19.4628 & 9.6298 & 7.6950 & 6.6091 & 9.8569 \\
$\mathrm{RMSE} \times 10^{-3}$ & & & & \\
\hline
\end{tabular}

Table 13. Seven estimated parameters of the polycrystalline SW255 module at different irradiance conditions.

\begin{tabular}{cccccc}
\hline $\mathrm{E}\left(\mathrm{W} / \mathrm{m}^{2}\right)$ & 1000 & 800 & 600 & 400 & 200 \\
Parameters & 8.8928 & 7.1234 & 5.3394 & 3.5655 & 1.7817 \\
\hline$I_{r}(\mathrm{~A})$ & $6.9030 \mathrm{e}-08$ & $7.6854 \mathrm{e}-08$ & $3.4988 \mathrm{e}-08$ & $7.6950 \mathrm{e}-08$ & $7.3365 \mathrm{e}-08$ \\
$I_{o 1}(\mathrm{~A})$ & $5.9342 \mathrm{e}-08$ & $2.7425 \mathrm{e}-07$ & $4.1686 \mathrm{e}-07$ & $1.1246 \mathrm{e}-07$ & $2.1394 \mathrm{e}-07$ \\
$I_{o 2}(\mathrm{~A})$ & 1.3213 & 1.3323 & 1.2802 & 1.9997 & 1.3338 \\
$n_{1}$ & 1.7503 & 1.7486 & 1.7352 & 1.3611 & 1.7746 \\
$n_{2}$ & 0.2200 & 0.2099 & 0.2154 & 0.1743 & 0.1150 \\
$R_{s}(\Omega)$ & 7114.9 & 3257.3 & 4515.6 & 2.9635 & 5.8048 \\
$R_{p}(\Omega)$ & 12.6607 & 14.7437 & 7.7546 & 8.7455 & 4.3193 \\
$\mathrm{RMSE} \times 10^{-3}$ & & & & & \\
\hline
\end{tabular}

Table 14. Comparison results of five algorithms for 20 independent tests.

\begin{tabular}{cccccccc}
\hline $\mathrm{E}\left(\mathrm{W} / \mathrm{m}^{2}\right)$ & Algorithm & $I_{r}(\mathrm{~A})$ & $I_{0}(\mathrm{~A})$ & $n$ & $R_{s}(\Omega)$ & $R_{p}(\Omega)$ & $\mathrm{RMSE} \times 10^{-3}$ \\
\hline \multirow{2}{*}{1000} & EVPS & $\mathbf{8 . 9 0 0 5}$ & $\mathbf{2 . 3 7 6 \mathrm { e } - 0 7}$ & $\mathbf{1 . 3 6 3 2}$ & $\mathbf{0 . 2 1 0 9}$ & $\mathbf{6 7 0 9 . 6}$ & $\mathbf{1 9 . 4 6 2 8}$ \\
& SSA & 8.9273 & $8.006 \mathrm{e}-07$ & 1.5197 & 0.17128 & 4693 & 46.829 \\
& WAO & 8.9035 & $5.1465 \mathrm{e}-07$ & 1.4798 & 0.18597 & 5992.3 & 44.717 \\
& MVO & 8.9045 & $1.7761 \mathrm{e}-07$ & 1.3908 & 0.20437 & 7999.1 & 24.565 \\
& GWO & 8.9465 & $3.4037 \mathrm{e}-07$ & 1.4437 & 0.19151 & 704.46 & 38.846 \\
& MFO & 8.9046 & $1.8009 \mathrm{e}-07$ & 1.3919 & 0.2036 & 8000 & 24.706 \\
\hline
\end{tabular}




\section{Continued}

\begin{tabular}{|c|c|c|c|c|c|c|c|}
\hline \multirow{6}{*}{800} & EVPS & 7.1156 & $6.8846 \mathrm{e}-08$ & 1.3212 & 0.2169 & 4428.5 & 9.6298 \\
\hline & SSA & 7.1487 & $1.0559 \mathrm{e}-06$ & 1.55 & 0.14622 & 2741.4 & 41.995 \\
\hline & WAO & 7.1607 & $3.6348 \mathrm{e}-06$ & 1.6818 & 0.10242 & 5347 & 57.411 \\
\hline & MVO & 7.1496 & $7.078 \mathrm{e}-07$ & 1.5116 & 0.15786 & 1563.7 & 37.947 \\
\hline & GWO & 7.1452 & $8.0295 e-07$ & 1.5233 & 0.15771 & 5559.5 & 38.485 \\
\hline & MFO & 7.13 & $3.1117 \mathrm{e}-07$ & 1.4383 & 0.18167 & 8000 & 26.455 \\
\hline \multirow{6}{*}{600} & EVPS & 5.3376 & $6.8962 \mathrm{e}-08$ & 1.3222 & 0.2110 & 6065 & 7.6950 \\
\hline & SSA & 5.3434 & $1.5209 \mathrm{e}-07$ & 1.3822 & 0.18597 & 7677.2 & 14.248 \\
\hline & WAO & 5.3634 & $3.995 \mathrm{e}-06$ & 1.7014 & 0.018556 & 2647.7 & 54.056 \\
\hline & MVO & 5.3595 & $7.7029 \mathrm{e}-07$ & 1.5239 & 0.12557 & 7461.4 & 29.299 \\
\hline & GWO & 5.314 & $9.2173 \mathrm{e}-09$ & 1.1905 & 0.2572 & 3847.2 & 14.454 \\
\hline & MFO & 5.3513 & $3.5134 \mathrm{e}-07$ & 1.452 & 0.15616 & 6324.5 & 21.965 \\
\hline \multirow{6}{*}{400} & EVPS & 3.5635 & $6.8596 \mathrm{e}-08$ & 1.3232 & 0.1937 & 2177.7 & 6.6091 \\
\hline & SSA & 3.5633 & $1.9988 \mathrm{e}-07$ & 1.4076 & 0.14348 & 7882.9 & 11.392 \\
\hline & WAO & 3.6325 & $2.5137 \mathrm{e}-06$ & 1.6575 & 0.06760 & 3564.3 & 45.294 \\
\hline & MVO & 3.5721 & $1.7561 \mathrm{e}-07$ & 1.3968 & 0.14598 & 1496.1 & 12.517 \\
\hline & GWO & 3.5808 & $1.5835 \mathrm{e}-06$ & 1.6058 & 0.018474 & 7752.8 & 24.66 \\
\hline & MFO & 3.5641 & $1.9926 \mathrm{e}-07$ & 1.4072 & 0.14678 & 8000 & 11.277 \\
\hline \multirow{6}{*}{200} & EVPS & 1.7760 & $6.8830 \mathrm{e}-08$ & 1.3264 & 0.1942 & 2742.4 & 9.8569 \\
\hline & SSA & 1.7846 & $2.2927 \mathrm{e}-07$ & 1.4259 & 0.012545 & 4636.4 & 7.0205 \\
\hline & WAO & 1.7692 & $1.5472 \mathrm{e}-07$ & 1.3919 & 0.0010176 & 5259 & 11.009 \\
\hline & MVO & 1.7897 & $6.1994 \mathrm{e}-08$ & 1.3178 & 0.12359 & 1323.6 & 6.1192 \\
\hline & GWO & 1.808 & $6.1509 \mathrm{e}-07$ & 1.5204 & 0.034513 & 1733.9 & 18.224 \\
\hline & MFO & 1.7897 & $8.3885 \mathrm{e}-08$ & 1.3415 & 0.001 & 898.89 & 14.321 \\
\hline
\end{tabular}

Table 15. Sharp ND-R250A5 module parameter.

\begin{tabular}{cc}
\hline Parameters & Values \\
\hline$I_{s c}(\mathrm{~A})$ & 8.68 \\
$V_{o c}(\mathrm{~V})$ & 37.6 \\
$I_{m} p(\mathrm{~A})$ & 8.10 \\
$V_{m p}(\mathrm{~V})$ & 30.9 \\
$N_{s}$ & 60 \\
\hline
\end{tabular}

Table 16. Lower and upper bound.

\begin{tabular}{ccc}
\hline Parameters & Lower Bound & Upper Bound \\
\hline$I_{r}(\mathrm{~A})$ & 0 & 10 \\
$I_{o}(\mathrm{~A})$ & $1 \mathrm{e}-12$ & $1 \mathrm{e}-5$ \\
$n$ & 0.5 & 2.5 \\
$R_{s}(\Omega)$ & 0.001 & 2 \\
$R_{p}(\Omega)$ & 0.001 & 5000 \\
\hline
\end{tabular}


Table 17. Best result for case study 4.

\begin{tabular}{cc}
\hline Parameters & EVPS \\
\hline$I_{r}(\mathrm{~A})$ & 9.146656 \\
$I_{o}(\mu \mathrm{A})$ & 1.094195 \\
$n$ & 1.213629 \\
$R_{s}(\Omega)$ & 0.589391 \\
$R_{p}(\Omega)$ & 4999.9999 \\
$\mathrm{OF}\left(\mathrm{RMSE} \times 10^{-3}\right)$ & 11.252719 \\
\hline
\end{tabular}

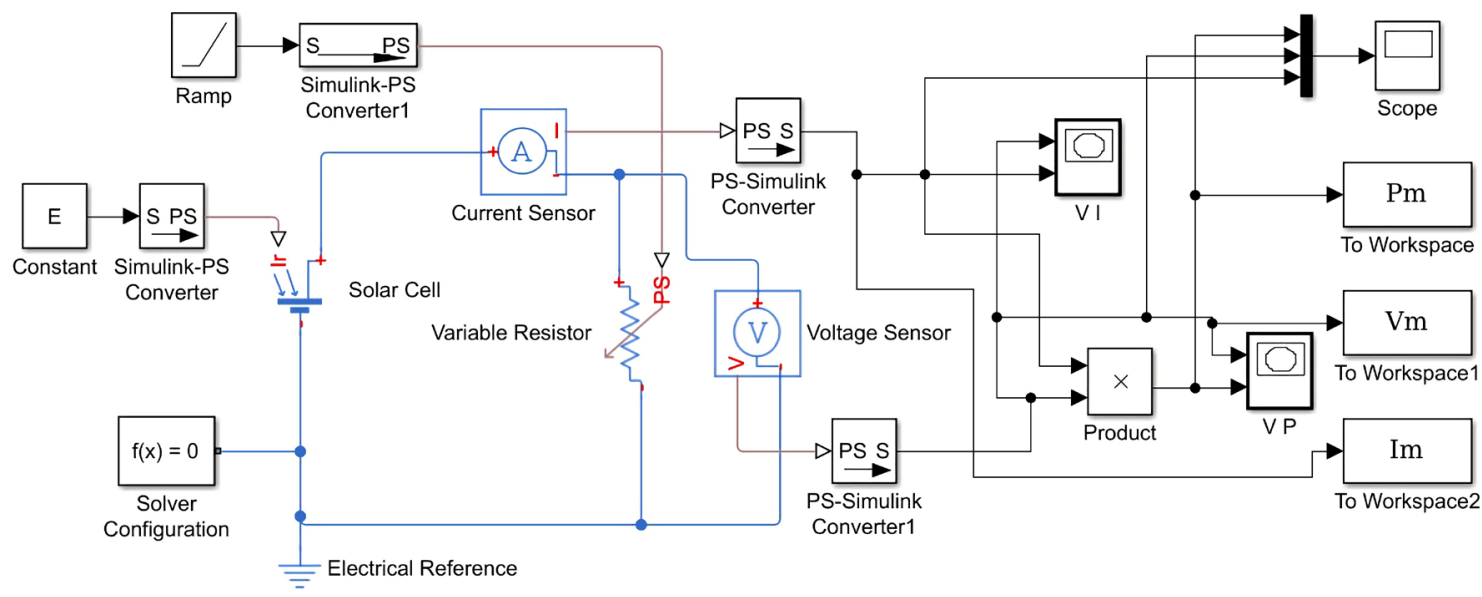

Figure 9. Simulink model of polycrystalline SW255.

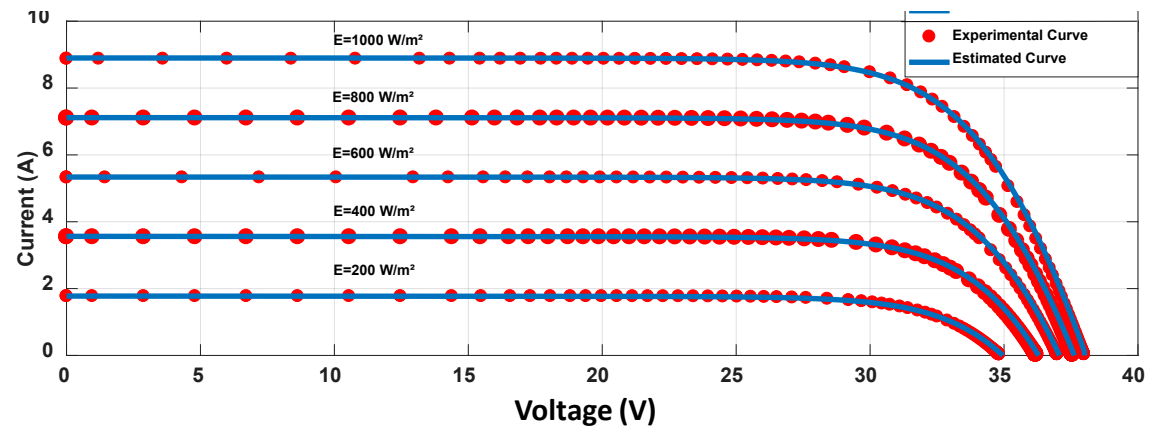

Figure 10. I-V characteristic of the measured and estimated curve.

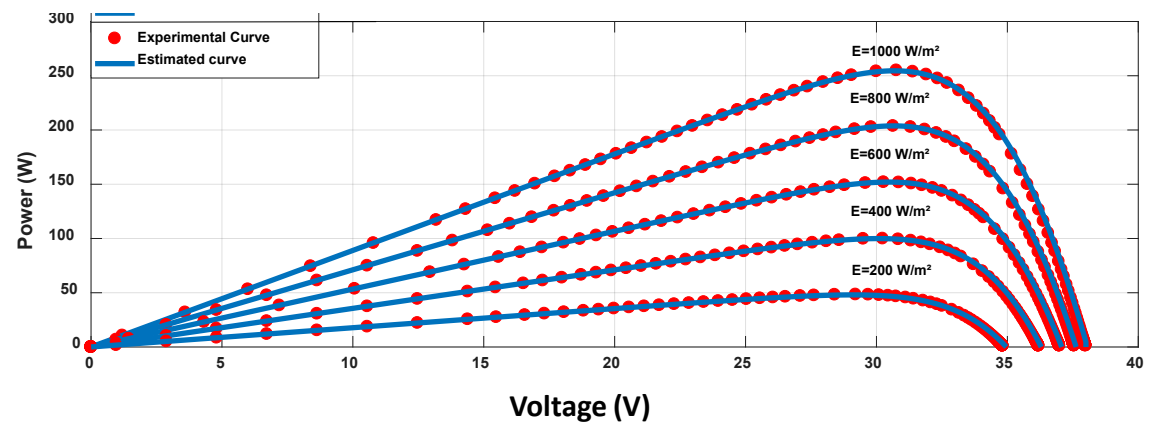

Figure 11. P-V characteristic of the measured and estimated curve. 


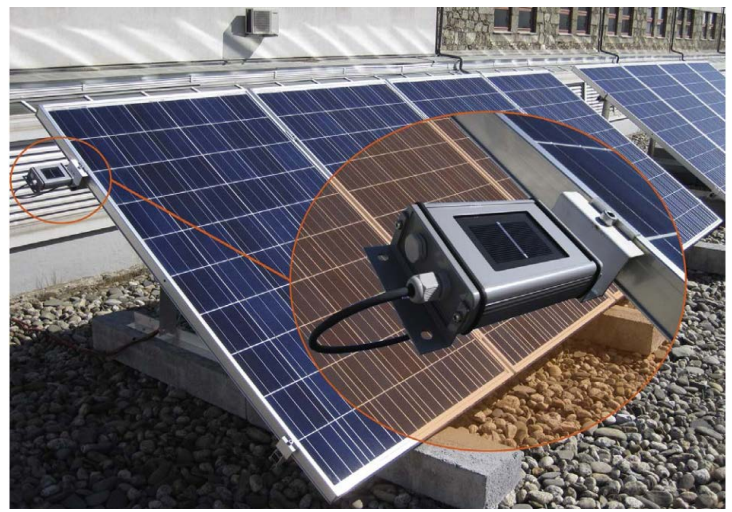

Figure 12. Experimental environment.

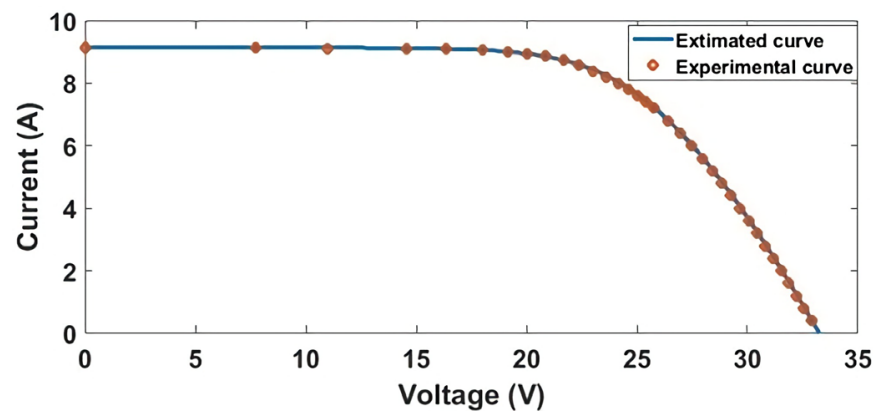

Figure 13. I-V characteristic of the measured and estimated curve.

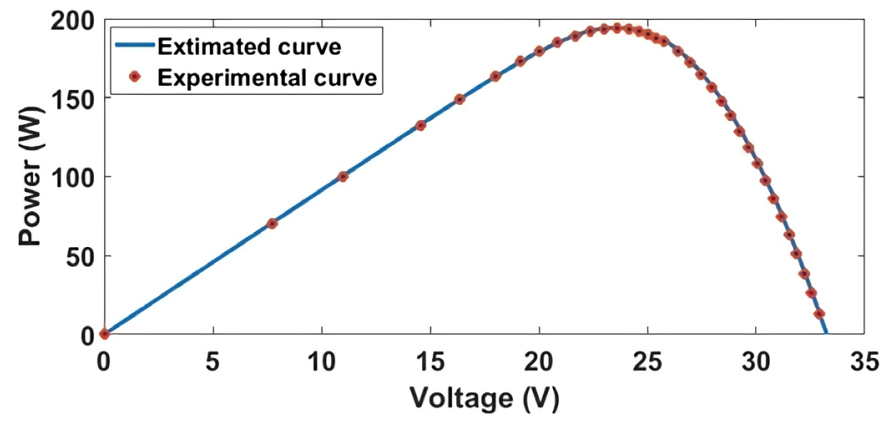

Figure 14. P-V characteristic of the measured and estimated curve.

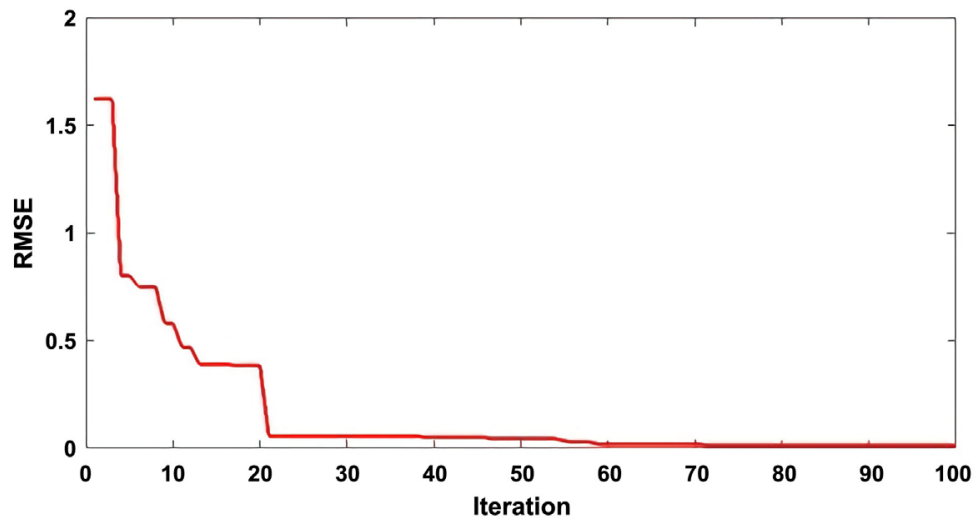

Figure 15. Convergence curve during the parameter extraction for the one diode model ND_R250A5 solar cell. 


\section{Conclusions}

In this paper, we have presented a novel bio-inspired optimizer of a very recent heuristic-based on technique, namely enhanced vibrating particles system to extract the best values of parameters of a photovoltaic cell. The particles are randomly initialized in an $n$-dimensional search space and Step-by-Step, they approach their equilibrium positions.

To show the performance of the algorithm, many cases have been implemented from one and two diodes model. The current-voltage and power-voltage characteristic of measured and estimated data show the best accuracy of the method. The simulations result and comparisons with another method exhibit high accuracy and validity of the proposed Enhanced Vibrating particles system to extract parameters of a photovoltaic cell and module. Thus, enhanced vibrating particles system can be recommended as an efficient method not only to extract the best parameters of a PV cell and module, but also to solve optimization problems in power systems. As every algorithm, enhanced vibrating particles system has some drawback like the variability of the result at each independent test and the limit of the algorithm to solve the only mono-objective problem. In the future work, the stability of the enhanced vibrating particles system should be improved and other parameters should be added to permit the algorithm to solve multi-objective optimization in power systems.

\section{Conflicts of Interest}

The authors declare no conflicts of interest regarding the publication of this paper.

\section{References}

[1] Wapet, M., et al. (2016) Optimisation bi-objectif des centrales thermiques par une méthode hybride incluantl'intelligence artificielle, Sciences, Technologies et Développement. Edition spéciale, 45-48.

[2] Hassan, M., Rabhi, A., El hajjaji, A. and Tina, G.M. (2017) Real Time Fault Detection in Photovoltaic Systems. Energy Procedia, 111, 914-923. https://doi.org/10.1016/j.egypro.2017.03.254

[3] International Energy Agency (IEA) (1992-2016) A Snapshot of Global PV.

[4] Tian, H., Mancilla-David, F., Ellis, K., Muljad, E. and Jenkins, P. (2012) Cell to Module Array Detailed Model for Photovoltaic Panels. Solar Energy, 86, 2695-2706. https://doi.org/10.1016/j.solener.2012.06.004

[5] Shukla, K.N., Saroj, R. and Sudhakar, K. (2015) Comparative Study of Isotropic and Anisotropic Sky Models to Estimate Solar Radiation Incident on Tilted Surface: A Case Study for Bhopal, India. Energy Reports, 1, 96-103. https://doi.org/10.1016/j.egyr.2015.03.003

[6] Shukla, K.N., Saroj, R. and Sudhakar, K. (2016) Mathematical Modelling of Solar Radiation Incident on Tilted Surface for Photovoltaic Application at Bhopal, MP, India. International Journal of Ambient Energy, 37, 579-588.

https://doi.org/10.1080/01430750.2015.1023834 
[7] Villella, M.G. and Gazoli, J.R. (2009) Comprehensive Approach to Modelling and Simulation of Photovoltaic Arrays. IEEE Transactions on Power Electronics, 24, 1198-1208. https://doi.org/10.1109/TPEL.2009.2013862

[8] Al-Hamadi, H. (2014) Estimation of Photovoltaic Cell Parameters Using. Piecewise Linear Approximation. International Journal of Computer Science and Electronics Engineering, 2, 2320-4028.

[9] Lo Brano, V. and Ciulla, G. (2013) An Efficient Analytical Approach for Obtaining a Five Parameters Model of Photovoltaic Modules Using Only Reference Data. Applied Energy, 111, 894-903. https://doi.org/10.1016/j.apenergy.2013.06.046

[10] Tamrakar, R. and Gupta, A. (2015) A Review: Extraction of Solar Cell Modelling. International Journal of Innovative Research in Electrical, Electronics, Instrumentation and Control Engineering, 3, 55-60. https://doi.org/10.17148/IJIREEICE.2015.3111

[11] Nunes, H.G.G., Pomboa, J.A.N., Marianoa, S.J.P.S., Caladoa, M.R.A. and Felippe de Souza, J.A.M. (2018) A New High Performance Method for Determining the Parameters of PV Cells and Modules Based on Guaranteed Convergence Particle Swarm Optimization. Applied Energy, 211, 774-791. https://doi.org/10.1016/j.apenergy.2017.11.078

[12] Jacob, B., et al. (2015) Solar PV Modeling and Parameter Extraction Using Artificial Immune System. Energy Procedia, 75, 331-336. https://doi.org/10.1016/j.egypro.2015.07.375

[13] Lun, S., Du, C.-J., Yang, G.-H., Wang, S., Guo, T.-T., Sang, J.-S. and Li, J.-P. (2013) An Explicit Approximate I-V Characteristic Model of a Solar Cell Based on Padé Approximate. Solar Energy, 92, 147-159. https://doi.org/10.1016/j.solener.2013.02.021

[14] Jain, A. and Kapoor, A. (2004) Exact Analytical Solutions of the Parameters of Real Solar Cells Using Lambert W-Function. Solar Energy Materials \& Solar Cells, 81, 269-277. https://doi.org/10.1016/j.solmat.2003.11.018

[15] Lun, S., Lun, S.-X., Du, C.-J., Guo, T.-T., Wang, S., Sang, J.-S. and Li, J.-P. (2013) A New Explicit I-V Model of a Solar Cell Based on Taylor's Series Expansion. Solar Energy, 94, 221-232. https://doi.org/10.1016/j.solener.2013.04.013

[16] De Blas, M., Torres, J.L., Prieto, E. and Garcia, A. (2002) Selecting a Suitable Model for Characterizing Photovoltaic Devices. Renewable Energy, 25, 371-380. https://doi.org/10.1016/S0960-1481(01)00056-8

[17] Brano, V.L. and Ciulla, G. (2013) An Efficient Analytical Approach for Obtaining a Five Parameters Model of Photovoltaic Modules Using Only Reference Data. Applied Energy, 111, 894-903. https://doi.org/10.1016/j.apenergy.2013.06.046

[18] Subudhi, B. and Pradhan, R. (2014) Development of New Parameter Extraction Scheme and Maximum Power Point Tracking System. PHD Thesis, National Institute of Technology, Rourkela.

[19] Yetayew, T.T. and Jyothsna, T.R. (2015) Parameter Extraction of Photovoltaic Modules Using Newton Raphson and Simulated Annealing Techniques. IEEE Power, Communication and Information Technology Conference, Bhubaneswar, 15-17 October 2015. https://doi.org/10.1109/PCITC.2015.7438166

[20] Ishaque, K., Salam, Z. and Taheri, H. (2011) Accurate MATLAB Simulink PV System Simulator Based on a Two-Diode Model. Journal of Power Electronics, 11, 179-187. https://doi.org/10.6113/JPE.2011.11.2.179

[21] Ghani, F., Fernandez, E.F., Almonacid, F. and O’Donovan, T.S. (2017) The Numerical Computation of Lumped Parameter Values Using the Multi-Dimensional 
Newton-Raphson Method for the Characterisation of a Multi-Junction CPV Module Using the Five-Parameter Approach. Solar Energy, 149, 302-313. https://doi.org/10.1016/j.solener.2017.04.024

[22] Gradella, M., Gazoli, J.R. and Filho, E.R. (2009) Comprehensive Approach to Modeling and Simulation of Photovoltaic Arrays. IEEE Transactions on Power Electronics, 24, 1198-1208. https://doi.org/10.1109/TPEL.2009.2013862

[23] Tossa, A.K., Soro, Y.M., Azoumah, Y. and Yamegueu, D. (2014) A New Approach to Estimate the Performance and Energy Productivity of Photovoltaic Modules in Real Operating Condition. Solar Energy, 110, 543-560. https://doi.org/10.1016/j.solener.2014.09.043

[24] Appelbaum, J. and Peled, A. (2014) Parameters Extraction of Solar Cells-A Comparative Examination of Three Methods. Solar Energy, Materials \& Solar Cells, 122, 164-173. https://doi.org/10.1016/j.solmat.2013.11.011

[25] Jervase, J.A., Bourdoucen, H. and Al-Lawati, A. (2001) Solar Cell Parameter Extraction Using Genetic Algorithms. Measurement Science and Technology, 12, 1922-1925. https://doi.org/10.1088/0957-0233/12/11/322

[26] Darmansyah, I.R. (2017) Photovoltaic Parameter Estimation Using Grey Wolf Optimization. 3rd International Conference on Control, Automation and Robotics, Nagoya, 22-24 April 2017. https://doi.org/10.1109/ICCAR.2017.7942766

[27] Wang, X. and Xu, Y. (2009) Parameter Extraction of Solar Cells Using Particle Swarm Optimization. Journal of Applied Physics, 105, Article ID: 094502. https://doi.org/10.1063/1.3122082

[28] Allam, D., Yousri, D.A. and Eteib, M.B. (2016) Parameters Extraction of the Three Diode Model for the Multi-Crystalline Solar Cell/Module Using Moth-Flame Optimization Algorithm. Energy Conversion and Management, 123, 535-548. https://doi.org/10.1016/j.enconman.2016.06.052

[29] Askarzadeh, A. and Rezazadeh, A. (2012) Parameter Identification for Solar Cell Models Using Harmony Search-Based Algorithms. Solar Energy, 86, 3241-3249. https://doi.org/10.1016/j.solener.2012.08.018

[30] Galphade, R. (2017) Electrical Characterization of a Photovoltaic Module through Artificial Neural Network: A Review. American Journal of Electrical Power and Energy Systems, 3, 14-20. https://doi.org/10.11648/j.ijecec.20170301.12

[31] Ali, E.E., El-Hameed, M.A., El-Fergany, A.A. and El-Arin M.M. (2016) Parameter Extraction of Photovoltaic Generating Units Using Multi-Verse Optimizer. Sustainable Energy Technologies and Assessments, 17, 68-76.

https://doi.org/10.1016/j.seta.2016.08.004

[32] Saida, M. and Kheldoun, A. (2017) Bond Graph Based Modelling for Parameter Identification of Photovoltaic Module. Energy, 141, 1456-1465. https://doi.org/10.1016/j.energy.2017.11.077

[33] Ma, J., Ting, T.O., Man, K.L., Zhang, N., Guan, S.-U. and Wong, P.W.H. (2013) Parameter Estimation of Photovoltaic Models via Cuckoo Search. Journal of Applied Mathematics, 2013, Article ID: 362619. https://doi.org/10.1155/2013/362619

[34] Subudhi, B. (2017) Bacterial Foraging Optimization Approach to Parameter Extraction of a Photovoltaic Module. Transactions on Sustainable Energy, 9, 381-389. https://doi.org/10.1109/TSTE.2017.2736060

[35] Yu, K., Liang, J.J., Qu, B.Y., Cheng, Z. and Wang, H. (2018) Multiple Learning Backtracking Search Algorithm for Estimating Parameters of Photovoltaic Models. Applied Energy, 226, 408-422. https://doi.org/10.1016/j.apenergy.2018.06.010 
[36] Omnia, S., Hasanien, H.M., Elgendy, M.A. and Abdeen, A.M. (2017) Whale Optimisation Algorithm for Photovoltaic Model Identification. Journal of Engineering, 2017, 1906-1911. https://doi.org/10.1049/joe.2017.0662

[37] Abbassi, R., Abbassi, A., Heidari, A.A. and Mirjalili, S. (2019) An Efficient Salp Swarm-Inspired Algorithm for Parameters Identification of Photovoltaic Cell Models. Energy Conversion and Management, 179, 362-372. https://doi.org/10.1016/j.enconman.2018.10.069

[38] Razmjooy, N., Khalilpour, M. and Ramezani, M. (2016) A New Meta-Heuristic Optimization Algorithm Inspired by FIFA World Cup Competitions: Theory and Its Application in PID Designing for AVR System. Journal of Control, Automation and Electrical Systems, 27, 419-440. https://doi.org/10.1007/s40313-016-0242-6

[39] Namadchian, A., Ramezani, M. and Razmjooy, N. (2016) A New Meta-Heuristic Algorithm for Optimization Based on Variance Reduction of Guassian Distribution. Majlesi Journal of Electrical Engineering, 10, 49.

[40] Razmjooy, N. and Ramezani, M. (2014) An Improved Quantum Evolutionary Algorithm Based on Invasive Weed Optimization. Indian Journal of Scientific Research, 4, 413-422.

[41] Razmjooy, N. and Ramezani, M. (2016) Training Wavelet Neural Networks Using Hybrid Particle Swarm Optimization and Gravitational Search Algorithm for System Identification. International Journal of Mechatronics, Electrical and Computer Technology, 6, 2987-2997.

[42] Wolpert, D.H. and Macready, W.G. (1997) No Free Lunch Theorems for Optimization. IEEE Transactions on Evolutionary Computation, 1, 67-82. https://doi.org/10.1109/4235.585893

[43] El-Naggar, K.M., AlRashidi, M.R., AlHajri, M.F. and Al-Othman, A.K. (2012) Simulated Annealing Algorithm for Photovoltaic Parameters Identification. Solar Energy, 86, 266-274. https://doi.org/10.1016/j.solener.2011.09.032

[44] Oliva, D., Cuevas, E. and Pajares, G. (2014) Parameter Identification of Solar Cells Using Artificial Bee Colony Optimization. Energy, 72, 93-102. https://doi.org/10.1016/j.energy.2014.05.011

[45] El-Fergany, A. (2015) Efficient Tool to Characterize Photovoltaic Generating Systems Using Mine Blast Algorithm. Electric Power Components and Systems, 43, 890-901. https://doi.org/10.1080/15325008.2015.1014579

[46] Kaveh, A. and Ilchi Ghazaan, M. (2017) A New Meta-Heuristic Algorithm: Vibrating Particles System. Scientia Iranica, 24, 551-556. https://doi.org/10.24200/sci.2017.2417

[47] Kaveh, A.S.R., Vaez, H. and Hosseini, P. (2017) Enhanced Vibrating Particles System Algorithm for Damage Identification of Truss Structures. Scientia Iranica, 26, 246-256. https://doi.org/10.24200/sci.2017.4265

[48] Easwarakhanthan, T., Bottin, J., Bouhouch, I. and Boutrit, C. (1986) Nonlinear Minimization Algorithm for Determining the Solar Cell Parameters with Microcomputers. International Journal of Solar Energy, 4, 1-12. https://doi.org/10.1080/01425918608909835

[49] Rezae, A. (2016) Time Varying Acceleration Coefficients Particle Swarm Optimisation (TVACPSO): A New Optimisation Algorithm for Estimating Parameters of PV Cells and Modules. Energy Conversion and Management, 129, 262-274. https://doi.org/10.1016/j.enconman.2016.09.085

[50] Lim, L.H.I., Ye, Z., Ye, J., Yang, D. and Du, H. (2015) A Linear Identification of 
Diode Models from Single I-V Characteristics of PV Panels. IEEE Transactions on Industrial Electronics, 62, 4181-4193. https://doi.org/10.1109/TIE.2015.2390193

[51] Jiang, L., Maskell, D.L. and Patra, J.C. (2013) Parameter Estimation of Solar Cells and Modules Using an Improved Adaptive Differential Evolution Algorithm. Applied Energy, 112, 185-193. https://doi.org/10.1016/j.apenergy.2013.06.004

[52] AlHajri, M.F., El-Naggar, K.M., AlRashidi, M.R. and Al-Othman, A.K. (2012) Optimal Extraction of Solar Cell Parameters Using Pattern Search. Renewable Energy, 44, 238e245. https://doi.org/10.1016/j.renene.2012.01.082

[53] Laudani, A., Fulginei, F.R. and Salvini, A. (2014) High Performing Extraction Procedure for the One-Diode Model of a Photovoltaic Panel from Experimental I-V Curves by Using Reduced Forms. Solar Energy, 103, 316-326. https://doi.org/10.1016/j.solener.2014.02.014

[54] Chaibi, Y., Salhi, M., El-Jouni, A. and Essadki, A. (2018) A New Method to Extract the Equivalent Circuit Parameters of a Photovoltaic Panel. Solar Energy, 163, 376-386. https://doi.org/10.1016/j.solener.2018.02.017

[55] Wang, R., Zhan, Y. and Zhou, H. (2015) Application of Artificial Bee Colony in Model Parameter Identification of Solar Cells. Energies, 8, 7563-7581. https://doi.org/10.3390/en8087563

[56] Gnetchejo, P.J., et al. (2019) Important Notes on Parameter Estimation of Solar Photovoltaic Cell. Energy Conversion and Management, 197, 111870.

https://doi.org/10.1016/j.enconman.2019.111870 


\section{Nomenclature}

$E$ : Solar irradiance;

$F(\theta)$ : objective function to minimize;

I: cell output current $[\mathrm{A}]$;

$I_{\text {iext }}(\theta)$ : is the estimated current;

$I_{i, \text { mes }}$ : measured current $[\mathrm{A}]$;

$I_{\text {iext }}(\theta)$ : estimated current [A];

$I_{0}, I_{01}, I_{02}$ : Diode reverse saturation currents $[\mu \mathrm{A}]$;

$I_{d}, I_{d 1}, I_{d 2}$ : diode currents [A];

$I_{m p}$ current at the maximum power point [A];

$I_{r}$ photoelectric current [A];

$I_{s c}$ short-circuit current $[\mathrm{A}]$;

$k$. Boltzman constant [J/K];

$k_{i}$ : temperature coefficient of Isc $[\mathrm{A} / \mathrm{K}]$;

$n, n_{1}, n_{2}$ : Diode ideality factors;

$N$ : number of the experimental I-V data pairs;

$N_{S}$ : number of cells connected in series;

OF: objective function;

q. electron charge [C];

rand $_{1}$, rand $_{2}$, rand $_{3}$ : random numbers between $[0,1]$;

$R_{P}$ : parallel resistance $[\Omega]$;

$R_{S}$ : series resistance $[\Omega]$;

RMSE: root mean square error;

STC: Standard testing condition (1000 watts $\left./ \mathrm{m}^{2}, 25^{\circ} \mathrm{C}\right)$;

T: Temperature $[\mathrm{K}]$;

$V$ : cell output voltage $[\mathrm{V}]$;

$V_{i, \text { mes }}:$ measured voltage $[\mathrm{V}]$;

$V_{m p}$ : voltage at the maximum power point [V];

$V_{o c}$ : open-circuit voltage [V];

$V_{t}:$ thermal voltage [V];

$w_{1}, w_{2}, w_{3}$ : parameters;

$x_{j}^{i}$ : position of the particle;

$\theta$ : Parameters to estimate. 